UNIO - EU Law Journal. Vol. 4, No. 2, July 2018, pp 135-146.

®2018 Centre of Studies in European Union Law

School of Law - University of Minho

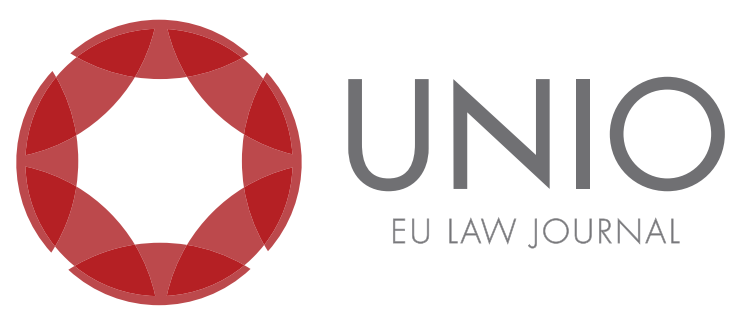

\title{
Robotics and AI in the European Union: opportunities and challenges
}

\section{Tiago Sérgio Cabral*}

ABSTRACT: The development of AI will bring with it a plethora of new economic and social opportunities. Areas that are as distinct as agriculture and health will be inevitably changed. However, this "new" technology also brings with it fundamental challenges and a new reality that our current legal framework is not yet prepared to deal with. In this paper, we will study the opportunities that AI brings to the European Union, the difficulties of regulating it, the current state of affairs, and the initiatives currently being drawn up to guarantee that the EU can keep up and even become a leader in this area. Our focus will be on the areas of health, labour market, liability rules and the challenges for the integration of robots in our daily lives.

KEYWORDS: Artificial Intelligence - roboethics - health - labour Market - liability.

\footnotetext{
* Master's student in EU Law at the University of Minho.
} 


\section{Introduction ${ }^{1}$}

In her opinion in the landmark judgement Zambrano ${ }^{2}$, the Advocate General Sharpston argued that: "when citizens move, they do so as buman beings, not as robots. They fall in love, marry and have families". Such reasoning might soon be outdated. It is certainly unlikely that citizens will start using their right of free movement with the coldness and insensitivity that characterizes the classical conception of robots. ${ }^{3}$ However, the issue is not precisely that one. The classical conception of robot is the one which is in danger of soon being outdated. Modern robots and AI are moving away from this stereotype and getting more buman-like. The fact is that robots and AI are already capable of feats indicating a relatively high level of intelligence. Computers are already seasoned traders in stock markets, recordist contestants in popular game shows, able to write music, to predict human behaviour and learn from it. ${ }^{4}$ Nowadays, one does not need to go very far to see an advanced AI, looking at a smartphone or a home assistant should suffice. The trend will probably keep accelerating and AI promises to change our world and the way we live. ${ }^{5}$

However, the self-learning ability ${ }^{6}$ that most of these machines have and need has its downsides too. In 2016, Microsoft launched an AI bot designed to interact and learn from users on Twitter while mimicking a teenage girl. "Tay's" capabilities were quite impressive, allowing her to have almost human conversations with users, but its self-learning function was its undoing. Unfortunately, not all humans are righteous upstanding citizens, and if we program Al's to closely mirror the users' behaviour, some of humanity's worst characteristics are bound to show up. In "Tay's" case, it was deliberately corrupted in a concerted effort by malicious users. The bot developed an unfortunate affinity for racist ideologies. Eventually, Microsoft had to shut "Tay" down. ${ }^{7}$

IBM's Jeopardy ace "Watson" also needed to install a "profanity filter" after

\footnotetext{
${ }^{1}$ This paper was selected amongst the essays presented to INTEROP Project researchers by the Master's students of the School of Law of the University of Minho in the last academic semester of 2017/2018 regarding the development of the Digital Single Market.

${ }^{2}$ See Judgment of the ECJ of 8 March 2011, Zambrano, Case C-34/09, ECLI:EU:C:2011:124.

${ }^{3}$ See "Just married!... right? Same-sex marriage and free movement of EU citizens - an account on the Opinion of Advocate General Wathelet in Coman and Others", Sophie Perez Fernandes, accessed April 2, 2018, https://officialblogofunio.com/2018/01/22/just-married-right-same-sex-marriageand-free-movement-of-eu-citizens-an-account-on-the-opinion-of-advocate-general-wathelet-incoman-and-others/.

${ }^{4}$ See M. C. Elish and Danah Boyd, "Situating methods in the magic of Big Data and AI", Communication Monographs 85(1) (2018): 57-80; Opinion of the Advocate General delivered on 30 September 2010, Zambrano, Case C-34/09, ECLI:EU:C:2010:560.

${ }^{5}$ See Spyros Makridakis, "The forthcoming Artificial Intelligence (AI) revolution: Its impact on society and firms", Futures 90 (2017): 46-60; "Computational Power and the Social Impact of Artificial Intelligence", Tim Hwang, accessed June 8, 2018, https://papers.ssrn.com/sol3/papers.cfm?abstract_id=3147971. ${ }^{6}$ See Harry Surden, "Machine Learning and Law”, Washington Law Review 89(1) (2014): 87-115;

${ }^{7}$ Even if they struggled somewhat in the process that fact is that Microsoft Seems to be making a great effort to rid their AI programs of any undesirable characteristics and are having some degree of success. The Company corrected Tay's and is even using AI to curb other issues caused by malicious users like fake news. See "We really need to take accountability", Microsoft CEO on the 'Tay' chatbot”, Charlie Moloney, accessed June 7, 2018, https:/ / chatbotsmagazine.com/we-really-need-totake-accountability-microsoft-ceo-on-the-tay-chatbot-2383ee83a6ba; "How Microsoft is Using AI to Tackle Fake News", James O Malley, accessed June 7, 2018, http://www.gizmodo.co.uk/2018/05/ how-microsoft-is-using-ai-to-tackle-fake-news/.
} 
memorizing the "Urban Dictionary" gave a bit too much colour to its language. ${ }^{8}$ Google's Allo messaging app also had its issues bias, suggesting the emoji "person wearing turban" as a response to a message including a handgun. ${ }^{9 / 10}$

Bugs in the programming or unexpected situations can also cause machines to malfunction. After falling asleep on the floor, a woman in South Korea woke up with her robot vacuum sucking her hair. The robot probably not expecting to find its owner in such a location, when confronted with hair on the floor, tried to clean it. ${ }^{11}$ Amazon Echo, usually known as "Alexa", has been known to laugh for no obvious reason. Alexa also has an affinity for listing the names of the nearest cemeteries and funeral homes to its owners unprompted. ${ }^{12}$

The truth is that even if everything is working according to plan, to complete the tasks that are entrusted to them, machines may have to make highly difficult ethical decisions. As an example, an autonomous care robot might find itself in a situation where it must choose between possible harm, including death, of its owner, and possible harm, including death, of a third party.

The development of the Digital Single Market is one of the European Union's main priorities ${ }^{13}$ and robotics should be front and center. The European Union (EU) has been lagging behind other economic powerhouses like the United States (US), China, and Japan. ${ }^{14}$ But on this issue, the EU seems driven to lead the other economic superpowers. The European Parliament already published a resolution in 2017 recommending the implementation of European-wide Civil law rules on robotics. Reacting to its initiative, the European Commission promised to "put forward a comprehensive European approach to artificial intelligence and robotics in the first half of 2018 ". ${ }^{15}$ Before that, the Committee

\footnotetext{
${ }^{8}$ See Dave Smith, "IBM's Watson Gets A 'Swear Filter' After Learning The Urban Dictionary”, accessed April 2, 2018, http:/ /www.ibtimes.com/ibms-watson-gets-swear-filter-after-learning-urbandictionary-1007734.

${ }^{9}$ About possible solutions to bias in AI, See "How Copyright Law Can Fix Artificial Intelligence's Implicit Bias Problem”, Amanda Levendowski, accessed June 5, 2018, https:/ / papers.ssrn.com/sol3/ papers.cfm?abstract_id=3024938.

${ }^{10}$ See "Offensive chat app responses highlight AI fails", Selena Larson, accessed April 2, 2018, http:/ / money.cnn.com/2017/10/25/technology/business/google-allo-facebook-m-offensive-responses / index.html.

${ }^{11}$ See Woodrow Hartzog, "Unfair and Deceptive robots”, Maryland Law Review 74(4) (2015): 785-830; “South Korean woman's hair 'eaten' by robot vacuum cleaner as she slept”, Justin McCurry, accessed April 2, 2018, https://www.theguardian.com/world/2015/feb/09/south-korean-womans-haireaten-by-robot-vacuum-cleaner-as-she-slept.

${ }^{12}$ See "Amazon Knows Why Alexa Was Laughing at Its Customers", Niraj Chokshi, accessed April 3, 2018, https://www.nytimes.com/2018/03/08/business/alexa-laugh-amazon-echo.html; "Alexa is laughing at users and creeping them out", Heather Kelly, accessed April 3, 2018, http://money.cnn. com/2018/03/07/technology/alexa-laughing/index.html.

${ }^{13}$ See Joana Covelo de Abreu, “O Mercado Único Digital e o seu desígnio políticoconstitucional: o impacto da Agenda Eletrónica Europeia nas soluções de interoperabilidade”, UNIO - EU Law Journal 3(1) (2017): 130-150; "E-justice: e-codex as the interoperable solution to a judicial integration?”, Joana Covelo de Abreu, accessed June 8, 2018, https://officialblogofunio.com/2018/06/07/editorialof-june-2018/; "Promotion of internet connectivity in local communities ("WIFI4EU" legislative framework): deepening European Digital Single Market through interoperability solutions”, Joana Covelo de Abreu, accessed June 8, 2018.

${ }^{14}$ See "Competition, coin mining and plastic memories: why the EU should watch the Web Summit carefully", Tiago Sérgio Cabral, accessed June 7, 2018, https:/ / officialblogofunio.com/2017/11/14/ competition-coin-mining-and-plastic-memories-why-the-eu-should-watch-the-web-summitcarefully/.

15 "Policy: Artificial Intelligence", European Commission, accessed April 3, 2018, https://ec.europa.
} 
on Legal Affairs had already commissioned a study regarding European Civil Law Rules in Robotics. ${ }^{16}$ The European Economic and Social Committee also took the initiative of giving its opinion regarding this issue. ${ }^{17}$ Prompted by all these initiatives, the European Commission finally started giving proper shape to the EU's AI policy with the Communication on Artificial Intelligence for Europe. ${ }^{18}$

Our focus in this paper will be to study the opportunities that AI brings to the European Union, the challenges of regulating this "new" technology, the current state of affairs, and the initiatives currently being drawn up to guarantee that Europe can keep up and even become a leader in this area. ${ }^{19}$

\section{The opportunities and the challenges lying ahead}

\subsection{Do European fear robots?}

The European Civil Law Rules in Robotics study commissioned by the European Parliament's Legal Affairs Committee draws attention to an interesting phenomenon, often ignored in the discussion of robots and AI regulation. How will the cultural traditions of the EU Member States affect their stance on this issue? ${ }^{20}$

Both the Study and the Parliament's resolution call upon a series of highly influential literary works to illustrate how the "fear of the robot" might be deeply ingrained in the western mind. Thus, society might resist the integration of autonomous and self-learning machines in our daily lives. The legislator must strike a difficult balance between trying to debunk baseless fears and taking the necessary precautions to avoid the possible dangers posed by AI.

There are two main theories regarding AI: one states that AI is inherently good to society and will help humans in achieving the next stage of evolution. This theory states that AI will be built by the people, work for the people and protect the interests of the people. Essentially, Lincoln's AI. On the other hand, there is the argument that $\mathrm{AI}$ is an inherently evil or doomsday scenario. It states that machines will eventually turn on their creators, replacing the human race. These are the two scenarios that drive the fiercest passions in discussions about the subject. However, it is important that we do not forget that there is the possibility of at least one third scenario. The scenario where nothing changes. AI and robots can exacerbate the problems currently

eu/digital-single-market/en/artificial-intelligence.

${ }^{16}$ See "European Civil Law Rules in Robotics", Nathalie Nevejans commissioned by the European Parliament's Committee on Legal Affairs, accessed May 15, 2018, http://www.europarl.europa.eu/ RegData/etudes/STUD/2016/571379/IPOL_STU(2016)571379_EN.pdf.

17 See "Opinion on artificial intelligence - The consequences of artificial intelligence on the (digital) single market, production, consumption, employment and society", European Economic and Social Committee, accessed June 15, 2018, https:// docs.google.com/viewer?url=http $\% 3 \mathrm{~A} \% 2 \mathrm{~F} \% 2 \mathrm{Fwebapi}$. eesc.europa.eu\%2Fdocumentsanonymous\%2Feesc-2016-05369-00-00-ac-tra-en.docx.

18 See "Communication from the Commission to the European Parliament, the European Council, the Council, the European Economic and Social Committee and the Committee of the Regions Artificial Intelligence for Europe”, European Commission, accessed June 20, 2018, http:/ / ec.europa. $\mathrm{eu} /$ newsroom/dae/document.cfm?doc_id=51625.

${ }^{19}$ One question that will not be deeply analyzed in this paper is the issue of autonomous vehicle. The reasons are various. Firstly, we intend to bring attention to some equality important issues that are being overshadowed by autonomous vehicles. Secondly, we feel that there are already plenty of good analysis focusing on autonomous vehicles. Thirdly there is the always present question of keeping the paper balanced in its scope.

20 The report is itself written in a, probably intentionally, biased way. It serves as an interesting reflex of the issue it tries to address. 
affecting our society like inequality (as would any technological advancement if badly used), but the issue is not in the nature of the technology. In this scenario, it is not the machines' fault that the final result is negative, it is ours, their creators. AI does not get out of control, does not try to replace humans as the main species of the planet, but nevertheless, the results are still not desirable and must be avoided. ${ }^{21}$

Debunking baseless fears is necessary because without doing so, the EU might "miss the train" on robotic development. European companies and start-ups dedicated to building autonomous machines can have their progress hindered by not being able to sell their product in their home market ${ }^{22}$, losing to, for example, Japanese and SouthKorean companies where robots are seen in a more positive light. ${ }^{23}$ European industry could lose its capacity to compete with foreign companies, European citizens when ill could feel uncomfortable in being aided by robots erasing the benefits that robotic development can bring to the quality of life of ill and senior citizens ${ }^{24}$, European students might not feel attracted to areas related to the development of robotics, etc..

However, and with all this in mind, the legislator must not ignore the dangers that autonomous robots and AI might bring to human civilization. Fact is that a plenty of respected scientists and industry leaders, like Stephen Hawking, Bill Gates, and Elon Musk, expressed their anxieties regarding robot and AI development, if unchecked. Furthermore, they warned that the "doomsday scenario" could indeed happen. Therefore, the legislator must implement safeguards to assure that autonomous machines work for or with humanity and never against it. ${ }^{25}$

\subsection{If things go wrong, who is liable?}

Liability is one of the hardest issues to tackle when dealing with robotics. On one hand, the legislator must consider the interests of the consumers in matters concerning their protection and access to appropriate compensation in cases of robot or AI malfunction. On the other hand, the self-learning ability of autonomous machines makes them unpredictable. This is called the foreseeability problem. ${ }^{26}$ Unpredictability

\footnotetext{
${ }^{21}$ Fact is that there are plenty of ways in which the development of AI might turn wrong and make it "go bad". External causes like the environment, human malice and negligence, or internal causes like its self-learning capabilities can all contribute to it. See Roman V. Yampolskiy, "Taxonomy of Pathways to Dangerous AI", in proceedings of 2nd International Workshop on AI, Ethics and Society (Arizona: Association for the Advancement of Artificial Intelligence, 2016), 143-148.

22 "Law and Regulation of Artificial Intelligence and robots - Conceptual Framework and Normative Implications", Nicolas Petit, accessed June 1, 2018, https://papers.ssrn.com/sol3/papers. cfm?abstract_id=2931339.

${ }^{23}$ The European Union is working on this issue, and recently appointed "52 experts to the new High Level Group on Artificial Intelligence. The Group, consisting of representatives of academia, business, and civil society, will support the implementation of the EU Communication on Artificial Intelligence published in April 2018”. Furthermore, the CE is launching the European AI Alliance that aims to provide a platform where people can contact in a forum style with member from the High Level Group on Artificial Intelligence. Both these initiatives, with a special emphasis on the second aim to increase the participation of civil society in the decision process in the EU, and that is especially important in such a delicate issue as robotics and AI.

${ }^{24}$ See Neil M. Richards and William D. Smart, "How should the law think about robots?", in Robot Law, ed. Ryan Calo, A. Michael Froomkin and Ian Kerr (Cheltenham: Edward Elgar Publishing, 2016): 3-22.

${ }^{25}$ See Janosch Delcker "In global AI race, Europe pins hopes on ethics", accessed June 7, 2018; "Myth and the EU study on Civil Law Rules in Robotics", Paula Boddington, accessed April 6, 2018, https:/ /www.cs.ox.ac.uk/efai/2017/01/12/myth-and-the-eu-study-on-civil-law-rules-in-robotics/.

${ }^{26}$ See Matthew U. Scherer, "Regulating Artificial Intelligence Systems: Risks, Challenges,
} 
poses a challenge to strict producer's liability. The manufacturer must assure that the product works as it is intended, but if the "product" is learning from external sources and adapting its behaviour to the - quite unpredictable - challenges of the world, is that even possible?

Liability rules that are too strict may curb innovation and hurt the EU's economy by delaying, or even preventing, the appearance of companies dedicated to riskier technologies. With "driverless vehicles the number of factors an automated system needs to take into account (street rules, other vehicles on the road, passers-by both abiding and violating the street code, complex environment)" ${ }^{37}$ might be enough to make companies think that if the rules are not advantageous in the EU, maybe developing those technologies in other countries could be a better solution. ${ }^{28}$

There are some problems with applying traditional liability to autonomous robots. Let us first analyse the case of manufacturer liability. Should the manufacturer be always liable for damages arising from the robot's action? By doing this, we might be keeping companies from investing in this technology - like we warned before - but it is undeniable that consumers would be quite well protected. On the other hand, if the manufacturer is only liable for the data inserted on the robot, we can protect companies from unjustly having to compensate for unpredictable errors (in an industry that is quite young), or from errors that are caused by the user. Still, in this scenario, the final consumer will see its protection fairly diminished and that might be undesirable because it can also diminish the confidence in the new technology. Furthermore, companies could feel less need to invest in failsafe mechanisms.

Going from the manufacturer to the final consumer, usually known as the user, one might ask whether the user should ever be liable for its robot's damages? If the answer is yes, should the consumer be liable only for intentionally tampering with the system or also by unintentionally feeding it data that could result in this damage? We cannot forget that we can have the same exact systems into two robots and still get different results due to data. Depending on the data provided to it, the way it "learns" changes and could create legal and ethically good scenarios or illegal and ethically bad ones. Microsoft's "Tay" is the perfect example of this. Without all the negative data that it was given by malicious users, it would be probably be just a fun and moderately successful attempt at another chatbot.

Now let us imagine a scenario where there is a robot in every house. The probability of them being fed negative data by their users is quite high. We just have to look at human society to see it. Furthermore, the fact that this can happen by negligence is quite important.

Now, if both manufacturer and user are liable, what is the relation between these two kinds of liability? Where is the burden of proof? As we can see the solutions brought by the traditional concept of liability can be too complex, confusing, and hard to implement. They can also be quite simple as with manufacturer liability for every damage that the robot causes, but this might pose serious economic questions and be quite unfair on the producers of these technologies. On the other hand, the

Competencies, And Strategies", Harvard Journal of Law \& Technology 23(2) (2016): 354-400.

${ }^{27}$ E. Palmerini et al., "RoboLaw: Towards a European framework for robotics regulation", Robotics and Autonomous Systems 86 (2016): 78-85.

${ }^{28}$ See "The Liability Problem for Autonomous Artificial Agents", Peter M. Asaro, accessed April 10, 2018, http:/ / peterasaro.org/writing/Asaro,\%20Ethics\%20Auto\%20Agents,\%20AAAI.pdf; "European Perspectives on an Emergent Law of Robotics”, Joanna Diane Caytas, accessed April 10, 2018, https:/ / papers.ssrn.com/sol3/papers.cfm?abstract_id $=2956958$. 
other simple solution - deeming the user liable for data that is given to him/her even unintentionally - can be equally unfair, burdening the user with the exigence of always being alert when in contact with the robot, and potentially turning people away from this new technology.

There are simple and more effective ways to achieve a proper result. Personhood ${ }^{29}$ will be an issue to think about further along the line when AI is advanced enough that it becomes a subject. ${ }^{30}$ When a robot is advanced enough to be liable, it will probably also be advanced enough to have rights and, thus, these discussions should probably be held together, but we need a solution that works while AI is not quite there yet. ${ }^{31}$

Mandatory insurance schemes, on the other hand, can be discussed in the present and are (most likely) adaptable to the first stage of AI development. Furthermore, such schemes have the advantage of neither burdening excessively manufacturers nor users while keeping the necessity of investing in failsafe solutions (to make premiums lower). Finally, it is a known solution that will not scare the general consumer away from AI. ${ }^{32}$

\subsection{My metal employee, my metal co-worker and my metal boss or robots in the labour market}

One of the areas where robotization is already causing a fair share of changes is in the labour market. ${ }^{33}$ If you opt to go to a Hotel in Tokyo, it is possible that you

\footnotetext{
${ }^{29}$ See Lawrence B. Solum, "Legal Personhood for Artificial Intelligences", North Carolina Law Review 70 (3) (1992): 1231-1287; Ben Allgrove, Legal Personality for Artificial Intellects: Pragmatic Solution or Science Fiction? (Master's diss., Oxford University: 2006).

${ }^{30}$ See Markus Häuser, "Do robots have rights? The European Parliament addresses artificial intelligence and robotics", accessed June, 6, 2018, http://www.cms-lawnow.com/ealerts/2017/04/ do-robots-have-rights-the-european-parliament-addresses-artificial-intelligence-and-robotics.

${ }^{31}$ See Mark Coeckelbergh, "Robot rights? Towards a social-relational justification of moral consideration" Ethics and Information Technology 12(3) (2010): 209-221; Annemarie Bridy, "Coding Creativity: Copyright and the Artificially Intelligent Author", Stanford Technology Law Review 5 (2012): 1-28; Kalin Hristov, "Artificial Intelligence and the Copyright Dilemma", IDEA - The Journal of the Franklin Pierce Center for Intellectual Property 57(3) (2017): 431-454; Toni M. Massaro, "Siri-ously? Free Speech Rights and Artificial Intelligence”, Northwestern University Law Review 110(6) (2016): 1169-1194.

${ }^{32}$ See Peter M. Asaro, "A Body to Kick, but Still No Soul to Damn: Legal Perspectives on Robotics", in The Ethical and Social Implications of Robotics, Patrick Lin, Keith Abney and George A. Bekey eds. (Cambridge: MIT PRESS, 2012), 169-186; Peter M. Asaro, "What Should We Want From a Robot Ethic?", International Review of Information Ethics 6 (2006): 10-16; The Liability Problem for Autonomous Artificial Agents, Peter M. Asaro, June 6, 2018, http://peterasaro.org/writing/Asaro,\%20Ethics\%20 Auto\%20Agents,\%20AAAI.pdf; "European Perspectives on an Emergent Law of Robotics", Joanna Diane Caytas, accessed June, 7, 2018, https://papers.ssrn.com/sol3/papers.cfm?abstract_ $\mathrm{id}=2956958$; E. Palmerini et al., "RoboLaw: Towards a European framework for robotics regulation" Robotics and Autonomous Systems 86 (2016), 78-85; "Extending Legal Protection to Social robots: The Effects of Anthropomorphism, Empathy, and Violent Behavior Towards Robotic Objects, "Kate Darling", accessed June 10, 2018, https://papers.ssrn.com/sol3/papers.cfm?abstract_id=2044797; "When Artificial Intelligence Systems Produce Inventions: The 3A Era and an Alternative Model for Patent Law”, Shlomit Yanisky-Ravid and Xiaoqiong Liu, accessed June 10, 2018, https://papers.ssrn.com/ sol3/papers.cfm?abstract_id=2931828; “Generating Rembrandt: Artificial Intelligence, Accountability and Copyright - The Human-Like Workers Are Already Here - A New Model", Shlomit Yanisky-Ravid and Samuel Moorhead, accessed June 10, 2018, https://papers.ssrn.com/sol3/papers.cfm?abstract_ id $=2957722$.

${ }^{33}$ See Mohammad Hossein Jarrahi, "Artificial intelligence and the future of work: Human-AI symbiosis in organizational decision making", Business Horizons (2018): in press.
} 
will not find a human, but a robot doing your check-in ${ }^{34}$. But one does not need to go to such lengths to understand that there is already some disconnection between the $20^{\text {th }}$ century concept of work and the current state of affairs. The internet has some degree of culpability in this context by allowing people to be in permanent communication and work from the other side of the world. Of course, by expanding the pool of possible workers, it also expands the competition between them. But AI might bring even more drastic changes.

We have scientific studies predicting that numbers as high as $47 \%$ of all job positions might be at risk of extinction. ${ }^{35}$ However, there are also studies pointing to lower figures, and, in fact, with the possible job creation arising from AI, there is the possibility that the numbers might even turn out to be positive. ${ }^{36}$ There are certain areas that will certainly benefit from AI without affecting the labour market in any negative way, those are the areas where there is labour shortage already, like agriculture and the care of elder people. Other areas cannot in the near future be entirely regulated by robots, even if they might create a shift in the type of work done by humans, like medicine and law. ${ }^{37}$

Nevertheless, it is important to have in mind that the time to act is probably now, while we are still on time to influence the future state of affairs instead of just being pulled by the strong tide of AI. It is paramount to invest in the formation of workers to ensure that they are prepared to assume the new types of positions that are coming with AI. SMEs should be particularly supported, due to their smaller financial resources, that can hinder their ability to provide this type of training and formation to their workers. Changes in the school curriculums to prepare students to deal with AI and the challenges posed by it are also a prerequisite and should be implemented as soon as possible.

It is also necessary to avoid the creation of a digital divide between companies. ${ }^{38}$ If only the richest companies are able to access the benefits of AI, this could render the smaller companies that make most of the European industrial tissue unable to compete. ${ }^{39}$ In a scenario that could prove even worse, we should look to the fact

\footnotetext{
${ }^{34}$ Daisuke Kikuchi, “'Strange' hotel, run by robots, opens near Tokyo; more to come”, accessed June 7, 2018, https://www.japantimes.co.jp/news/2017/03/15/business/strange-hotel-run-by-robotsopens-near-tokyo-more-to-come/\#.Wy6mqaczZPY.

${ }^{35}$ See Carl Benedikt Frey and Michael A. Osborne, “The Future of Employment”, accessed June 8, 2018, https://www.oxfordmartin.ox.ac.uk/downloads/academic/future-of-employment.pdf; "Automation to take 1 in 3 jobs in UK's northern centres, report finds", The Guardian, accessed May 12, 2018, https:// www.theguardian.com/technology/2018/jan/29/automation-to-take-1-in-3-jobs-in-uks-northerncentres-report-finds.

${ }^{36}$ The Website "Will robots Take My Job?" uses data from the 2013 Oxford Study Carl Benedikt Frey and Michael A. Osborne to show in an easy and searchable way what are the probabilities of robots replacing humans in a specific area. See "Will robots Take My Job?", accessed June 8, 2018, https:// willrobotstakemyjob.com; "The Future of Work Skills and Resilience for a World of Change", European Political Strategy Centre, accessed June 10, 2018, http://ec.europa.eu/epsc/sites/epsc/ files/strategic_note_issue_13.pdf.

${ }^{37}$ See Amitai Etzioni and Oren Etzioni, "Keeping AI Legal", Vanderbilt Journal of Entertainment \& Technology 19,1 (2016): 132-146; "A Rule of Persons, Not Machines: The Limits of Legal Automation", Frank A. Pasquale, accessed 8 June, 2018, https://papers.ssrn.com/sol3/papers. cfm?abstract_id=3135549; Cary Coglianese and David Lehr, "Regulating by Robot: Administrative Decision Making in the Machine-Learning Era”, Georgetown Law Journal 105 (2017): 1147-1223.

${ }^{38}$ See "Artificial Intelligence Policy: A Primer and Roadmap", Ryan Calo, accessed 9 June, 2018, https://papers.ssrn.com/sol3/papers.cfm?abstract_id=3015350.

${ }^{39}$ The European Commission Seems somewhat aware of this issue, and the stronger Horizon Europe,
} 
that most of the companies that are currently more advanced in the development of AI do not come from Europe, but instead from other economic blocs that are directly competing with EU in this new industry, like the United States and China. If these companies can expand their AI capabilities while the European ones cannot, this could have potentially disastrous impacts on the EU's economy. To avoid such a scenario, it is paramount to invest in the advancement of technology not only at State level, but also at European level. While it is indeed true that the new multiannual financial framework proposes new measures to help with this issue, like the strengthened Horizon Europe Program, they do not seem to be enough yet.

\subsection{Doctor AI}

The current European Healthcare system is facing great challenges from an ageing population. Chronic patients also represent a growing issue that must be addressed in a way that uses the fewest resources possible, but guarantees adequate standard of care.

$\mathrm{AI}$ and robots provide great opportunities for the future of medicine, they can help in treating and monitoring the elderly ${ }^{40}$, detecting and predicting diseases ${ }^{41}$ and bring new quality of life for people who previously had no hope for getting it back. In some areas where there is lack of available professionals, AI and robots can work in collaboration with the few professionals available to allow them to help more people without diminishing the standard of care. For example, in physiotherapy where there is usually a professional and a patient interacting for a limited number of hours a day, and where the patient's performance is not really measured. In this area, machines can help by allowing the patients to do part of their exercises at home, freeing some of the professional's time for other patients. ${ }^{42}$ While in the end, the human professional will always have to supervise and interact with the patient, it is possible to maximize to use of AI to allow the same or a superior standard of care and caring for more people. ${ }^{43}$

However, there are plenty of issues and incompatibilities with health and the development of AI. First, medicine is shifting from treating the disease by itself to treating the patient. Treating a disease without treating the person behind it is like

with $€ 100$ billion available for research and innovation in the proposal for the next Multiannual Financial Framework, may help with this issue. See "The Commission's proposal for Horizon Europe”, European Commission, accessed June 20, 2018, https:/ / ec.europa.eu/commission/sites/ beta-political/files/budget-may2018-horizon-europe-regulation_en.pdf.

40 See Amaya Arcelus et al., "Integration of Smart Home Technologies in a Health Monitoring System for the Elderly", in 21st International Conference on Advanced Information Networking and Applications Workshops (IEEE Computer Society: Canada, 2007); "Artificial intelligence is helping to transform the way elderly people are cared for", Anmar Frangoul, accessed June 7, 2018, https://www.cnbc. com/2018/05/03/ai-helping-to-transforming-elderly-health-care.html; Shahram Nourizadeh, "Medical and Home automation Sensor Networks for Senior Citizens Telehomecare", in 2009 IEEE International Conference on Communications Workshops (IEEE Computer Society: Germany, 2009).

41 See "Google's new AI algorithm predicts heart disease by looking at your eyes", James Vincent, accessed June 5, 2018, https:/ / www.theverge.com/2018/2/19/17027902/google-verily-ai-algorithmeye-scan-heart-disease-cardiovascular-risk; Eun-Jae Lee et al., "Deep into the Brain: Artificial Intelligence in Stroke Imaging” Journal of Stroke 19(3) (2017): 277-285.

42 See the Portuguese Sword Phoenix project by Sword Health. "Sword Phoenix", Sword Health, accessed June 10, 2018, https:/ /www.swordhealth.com/.

43 Giorgio Quer et al., "Augmenting diagnostic vision with AI", The Lancet 390, 10091 (2017): 221; Eric Topol, "Digital medicine: empowering both patients and clinicians", The Lancet 388, 10046 (2017): 740-741; Evan D Muse et al., "Towards a smart medical home", The Lancet 389, 10067 (2017): 358. 
trying to ensure that we plant the best type of seed and ignoring the conditions of the field's soil, and thus the holistic vision of medicine is gaining strength. With this in mind, we must ensure that doctors are able to collaborate with machines but are not replaced by them, because while a robot might be much more able to detect the disease, someone will still have to connect the diagnosis to the person. Therefore, medical liability laws must not be strict enough as to bind doctors entirely to the diagnosis given to them by robots, lest they create a scenario where we lose this ability and connection. Our doctors and AI should complement each other.

Our legal framework is not correctly adapted to the proper use of robotic helpers in healthcare. Currently, these machines are regulated by the Medical Devices Directive $^{44}$, a piece of legislation from 1993, which has plenty of limitations in dealing with this new reality. In fact, one must question if, in some cases, these solutions should not be treated as regular medicines instead of medical devices. Such is, in our opinion, the case of smart pills with sensors to help the medicine get where it needs to go in our body and to ensure compliance with the Doctor's orders. ${ }^{45}$

There is also, as usual, the issue of privacy, data, and data protection. ${ }^{46}$ Data is incredibly important for AI to learn. It is almost impossible for a programmer to "teach" AI certain things through algorithms, which makes data essential to correct this flaw. As an example, if we want to teach a Robot how to distinguish between cats and dogs, we do not program every possible characteristic for a cat and a dog in it using an algorithm, that would be a herculean effort for such a "simple" result. What we do is feed the Robot every possible picture of cats and dogs and tell it

\footnotetext{
${ }^{44}$ See Council Directive 93/42/EEC of 14 June 1993 concerning medical devices.

${ }^{45}$ See "Say hello to intelligent pills: Digital system tracks patients from the inside out.", Daniel Cressey, accessed June 10, 2018, https:/ / www.nature.com/news/say-hello-to-intelligent-pills-1.9823.

${ }^{46}$ See "The first steps of a revolution with a set date (25 May 2018): the "new" General Data Protection regime", Pedro Madeira Froufe, accessed June 17, 2018, https://officialblogofunio. com/2018/05/25/the-first-steps-of-a-revolution-with-a-set-date-25-may-2018-the-new-generaldata-protection-regime/; "Protecting our personal data in the $21^{\text {st }}$ century: why the new EU legal framework matters", Tiago Sérgio Cabral and Rita de Sousa Costa, accessed June 8, 2018, https:// officialblogofunio.com/2016/06/20/protecting-our-personal-data-in-the-21st-century-why-thenew-eu-eu-legal-framework-matters/; "Implications of the declaration of invalidity of the Directive 2006/24 on the retention of personal data (metadata) in the EU Member States: an approach to the judgment Tele 2 of 21 December 2016”, Alessandra Silveira and Pedro Miguel Freitas, accessed June 8, 2018, https://officialblogofunio.com/2017/01/22/implications-of-the-declaration-ofinvalidity-of-the-directive-200624-on-the-retention-of-personal-data-metadata-in-the-memberstates-of-the-eu-an-approach-to-the-judgment-tele-2-of-21-december-20/; "Data Protection Officer according to GDPR”, André Mendes Costa, accessed June 8, 2018, https://officialblogofunio. com/2017/06/13/2014/; "Data Protection, Data Transfers, and International Agreements: the CJEU's Opinion 1/15”, Christopher Kuner, accessed June 8, 2018, https:/ /verfassungsblog.de/dataprotection-data-transfers-and-international-agreements-the-cjeus-opinion-115/; "The EU General Data Protection Regulation: Powerful Tool for Data Subjects?", Enrico Peuker, accessed June 8, 2018, https://verfassungsblog.de/the-eu-general-data-protection-regulation-powerful-tool-for-datasubjects/; Alessandra Silveira and Pedro Miguel Freitas, "The recent jurisprudence of the CJEU on personal data retention: implications for criminal investigation in Portugal", UNIO - EU Law Journal 3(2) (2017): 45-56; “The Three Laws of Robotics in the Age of Big Data”, Jack M. Balkin, accessed June 8, 2018, https://papers.ssrn.com/sol3/papers.cfm?abstract_id=2890965; "Exploring or Exploiting? Social and Ethical Implications of Autonomous Experimentation in AI", Sarah Bird et al., accessed June 2, 2018, https:/ / papers.ssrn.com/sol3/papers.cfm?abstract_id=2846909; "Humans Forget, Machines Remember: Artificial Intelligence and the Right to Be Forgotten”, Eduard Fosch Villaronga, Peter Kieseberg and Tiffany Li, accessed 8 June, 2018, https://papers.ssrn.com/sol3/ papers.cfm?abstract_id $=3018186$.
} 
what pictures are of cats and what pictures are of dogs. The robot then is able to adapt to new pictures of cats and dogs and distinguish them using analogy. ${ }^{47 / 48}$ The exact same thing is used for cancer and other diseases with very good results. In fact, the self-learning capabilities of AI are bound by their need for data to do these kinds of operations. But in this process, there are some issues. We are trying to give control of their data back to the patients, to allow them to know what problems they have and, if they wish, take their data easily with them to new practitioners and countries. There are good reasons for this, someone who knows their problems usually tries harder to get better, and fewer sick people is obviously good socially and economically. In this manner, we also can control the exploitation of health data by companies for studies without the authorization of the patient. We also give the patient new freedom regarding their data, the individual can keep to itself, give to specific research or even sell it for a profit.

But health-related robots need this data for their learning capabilities to work, so what can we do if patients decide that they do not wish to allow robots to use their data to learn about diseases or if they want to charge excessive values for it that companies are not able to afford. We need to find an equilibrium between the rights of the patients and the good that can come from having robots and AI more developed in this area.

While on the issue of medical data, interoperability and portability are not only essential to guarantee that the citizen can take its data to another hospital and country and be treated there, but also for robots and AI. If the data is not compatible between systems, AI and robot developers will have to develop new ways for robots to learn from every type of format that could possibly be fed to them, increasing substantially the cost of developing robots in the European Union. Since there is no single country in the EU with the ability to provide data in enough quantity to compete with our main competitors like the United States and China, the Union intervenes to ensure that our data can be shared (if the legal requirements are met) between various countries without technical difficulties arising from incompatible systems. ${ }^{49}$

\section{Conclusion}

The changes that AI and Robotics will bring appear to be transversal to almost every area of our lives. While it is true that, currently, automation and more precisely, autonomous vehicles are the "hot topic" when it comes to AI, as we demonstrated, they are not the only challenge brought by AI and probably not even the most important.

The European Union begins at a double disadvantage in this race. Firstly, it starts quite late. Other economic blocs have already pretty much "embraced" the trend of AI and robotics. Secondly, European society and traditions paint machines

\footnotetext{
${ }^{47}$ However, there are certain limitations to this technology; one researcher from MIT was able to fool Google's AI recognition software by changing an image pixel by pixel. In one case, "an image of a dog that was wrongly identified as two people skiing". See New Scientist, "Google AI made to look foolish", New Scientist 237, 3159 (2018): 19.

${ }^{48}$ See "Artificial intelligence and fundamental rights: the problem of regulation aimed at avoiding algorithmic discrimination", Alessandra Silveira and Sophie Perez Fernandes, accessed July 8, 2018, https://officialblogofunio.com/2018/07/07/editorial-of-july-2018/.

${ }^{49}$ See E. Fosch Villaronga and A. Roig, "European regulatory framework for person carrier robots", Computer Law and Security Review 33(4) (2017): 502-520.
} 
as something negative, that will overthrow us in the future, and that makes European citizens naturally reluctant in the face of AI. The issue is that while some reluctance is needed - probably even healthy - and quite some renowned specialists recommend it -, too much of it might create further delays in the development of the technology, which will only cause the EU to fall further behind other economic blocs due to legislation that is excessively strict and disincentivizing to technology development.

One of the areas where such might happen is liability. It is evident that defining the rules of liability for $\mathrm{AI}$ is a completely new challenge for our legislator, and the instinctive reaction is to try to protect the consumer as much as possible against the "potentially evil" robots. Nevertheless, we should not give in to this temptation. Doing so might create a burden that is too great for our companies, and even protect users who created damages due to their malicious intents or negligent behaviour. One should never forget that there are limitations to what it is possible to program in AI, and the data inputs by the user will be extremely important in defining how a robot will behave, even if it has the same core programming.

Regulating AI will be quite a wearisome task, but we should not lose sight of the potential benefits of a well-regulated and properly developed AI industry. Some areas like healthcare might be revolutionized by it. With these developments, we might be able to further increase the standards of living of our populations, expand life expectancy, cure incurable diseases, and give our elders a better quality of life in their last living years. There are some challenges to it, since regulating AI in healthcare is particularly challenging due to the issue of data and how sensible is healthcare related data, but the rewards are probably worth the effort.

The same can be said about AI and the labour market. While AI is traditionally pictured as something that will replace human workers and is, thus, good for the economy as a whole, but bad for the common worker, this is not necessarily the truth. AI by itself in the workplace is not inherently "good" or "bad" and it cannot do all the work alone. Human workers will still be needed for quite some time to control machines and intervene in case something goes wrong. The type of work will change but the workers will still be needed and, thus, it is essential to prepare them for this shift by helping companies in giving training. Long term, if AI reaches the type of sophistication that allows it to do most of the work by itself, we might have to rethink our concept of work so as to ensure it evolves with technology, but also that it still ensures subsistence and dignity for the workers, while (hopefully) also giving them more free time. Such a solution may entail the redistribution of income that is being created by the robots to ensure that humans are still getting paid even if they are working fewer hours. But this scenario is still far out. Nevertheless, it might be the time to start seriously thinking about it, at least in theory. 